\title{
LGR5 in breast cancer and ductal carcinoma in situ: a diagnostic and prognostic biomarker and a therapeutic target
}

Catharina Hagerling ${ }^{1,2,3^{*}}$, Mark Owyong ${ }^{1}$, Vaishnavi Sitarama', Chih-Yang Wang ${ }^{1,4}$, Charlene Lin', Renske J. E. van den Bijgaart ${ }^{1,5}$, Charlotte D. Koopman ${ }^{1,6,7}$, Audrey Brenot ${ }^{1,8}$, Ankitha Nanjaraj ${ }^{1}$, Fredrik Wärnberg ${ }^{9}$, Karin Jirström², Ophir D. Klein ${ }^{10,11}$, Zena Werb ${ }^{1}$ and Vicki Plaks ${ }^{1,10^{*}}$

\begin{abstract}
Background: Novel biomarkers are required to discern between breast tumors that should be targeted for treatment from those that would never become clinically apparent and/or life threatening for patients. Moreover, therapeutics that specifically target breast cancer (BC) cells with tumor-initiating capacity to prevent recurrence are an unmet need. We investigated the clinical importance of LGR5 in BC and ductal carcinoma in situ (DCIS) to explore LGR5 as a biomarker and a therapeutic target.

Methods: We stained BC $(n=401)$ and DCIS $(n=119)$ tissue microarrays with an antibody against LGR5. We examined an LGR5 knockdown ER ${ }^{-}$cell line that was orthotopically transplanted and used for in vitro colony assays. We also determined the tumor-initiating role of Lgr5 in lineage-tracing experiments. Lastly, we transplanted ER ${ }^{-}$patient-derived xenografts into mice that were subsequently treated with a LGR5 antibody drug conjugate (anti-LGR5-ADC).

Results: LGR5 expression correlated with small tumor size, lower grade, lymph node negativity, and ER-positivity. ER ${ }^{+}$ patients with $L G R 5^{\text {high }}$ tumors rarely had recurrence, while high-grade $E R^{-}$patients with $L G R 5^{\text {high }}$ expression recurred and died due to BC more often. Intriguingly, all the DCIS patients who later died of BC had LGR5-positive tumors. Colony assays and xenograft experiments substantiated a role for LGR5 in $E R^{-}$tumor initiation and subsequent growth, which was further validated by lineage-tracing experiments in $E R^{-}$/triple-negative BC mouse models. Importantly, by utilizing LGR ${ }^{\text {high }}$ patient-derived xenografts, we showed that anti-LGR5-ADC should be considered as a therapeutic for high-grade $E R^{-} B C$.
\end{abstract}

Conclusion: LGR5 has distinct roles in $E R^{-}$vs. $E R^{+} B C$ with potential clinical applicability as a biomarker to identify patients in need of therapy and could serve as a therapeutic target for high-grade ER ${ }^{-} B C$.

Keywords: LGR5, Breast cancer, DCIS, Estrogen receptor, Targeted therapy

\footnotetext{
*Correspondence: catharina.hagerling@med.lu.se; vicki.plaks@ucsf.edu

'Department of Anatomy and the Helen Diller Family Comprehensive Cancer Center, University of California, San Francisco, CA 94143-0452, USA

Full list of author information is available at the end of the article
}

(c) The Author(s). 2020 Open Access This article is licensed under a Creative Commons Attribution 4.0 International License, which permits use, sharing, adaptation, distribution and reproduction in any medium or format, as long as you give appropriate credit to the original author(s) and the source, provide a link to the Creative Commons licence, and indicate if changes were made. The images or other third party material in this article are included in the article's Creative Commons licence, unless indicated otherwise in a credit line to the material. If material is not included in the article's Creative Commons licence and your intended use is not permitted by statutory regulation or exceeds the permitted use, you will need to obtain permission directly from the copyright holder. To view a copy of this licence, visit http://creativecommons.org/licenses/by/4.0/ The Creative Commons Public Domain Dedication waiver (http://creativecommons.org/publicdomain/zero/1.0/) applies to the data made available in this article, unless otherwise stated in a credit line to the data. 


\section{Background}

Overtreatment is a major challenge in the clinical management of breast cancer $[1,2]$. Two patient groups subjected to overtreatment are those with ductal carcinoma in situ (DCIS) and those with estrogen receptor-positive $\left(\mathrm{ER}^{+}\right)$breast cancer $(\mathrm{BC})[3,4]$.

Gene expression profiling of $\mathrm{BC}$ has enabled its classification into four clinically relevant $\mathrm{BC}$ subtypes; two $\mathrm{ER}^{+}$subtypes (Luminal A and Luminal B) with favorable clinical outcomes as compared to the two $\mathrm{ER}^{-}$subtypes (triple negative/basal-like and human epidermal growth factor receptor 2 (HER2) enriched) [5-8]. Patients with low-grade, $<2 \mathrm{~cm}, \mathrm{ER}^{+}$tumors have the most favorable outcome. DCIS tumors are a heterogeneous group of pre-invasive lesions [9-11]. While some DCIS tumors are predestined to acquire an invasive phenotype and progress into bona fide $\mathrm{BC}$, others never become invasive [9]. It is known that approximately $25-50 \%$ of DCIS tumors progress into invasive BC independent of DCIS tumor grade [12-15], a finding supported by genomic and transcriptomic data showing that DCIS share genetic similarities with invasive BC [16-19]. Similar to patients with DCIS tumors, approximately $50 \%$ of patients with low-grade ER+ tumors might end up receiving therapy without deriving clinical benefit [20]. Thus, to optimize patient care, there is a need to uncover novel diagnostic and prognostic biomarkers to discern between tumors that never become invasive and/or life threatening from those that should be targeted for treatment.

Targeted therapies against hormone receptors and HER2 in BC have improved overall survival over the past two decades, with the 5-year survival rates in several countries now approaching 90\% [21]. Despite these advances in risk stratification and therapy, treatment of patients with triple-negative $\mathrm{BC}$ (TNBC) remains a major clinical challenge. TNBC, an $\mathrm{ER}^{-}$, progesterone receptor (PR) negative and HER2 ${ }^{-} \mathrm{BC}$, is more likely to recur and disseminate with a lower 5-year survival rate as compared to other BC subtypes [22]. About 70-80\% of these cancers are also basal-like since they bear characteristics of basal epithelial breast cells [23-25]. The prognosis of TNBC tumors is often poor with limited effective treatment options [23, 24]. Additionally, many TNBC patients have metastatic disease at the time of diagnosis that responds poorly to conventional treatments, such as chemo- and radiotherapy [26]. Apart from a recent clinical study conducted by Genentech using chemotherapy, paclitaxel, and anti-PD-L1 checkpoint inhibitor, atezolizumab, that showed $40 \%$ greater progression free survival as compared to chemotherapy alone [27], there are currently no other approved targeted therapies for TNBC.

To uncover novel diagnostic and prognostic BC biomarkers that could potentially provide a backbone for the future development of targeted therapeutics, we interrogated the leucine-rich repeat containing Gprotein-coupled receptor 5 (LGR5). LGR5 potentiates canonical Wnt signaling and marks stem cells in various tissues, including the mammary gland [28-32]. We and others have previously shown that Lgr5 identifies bipotent mammary stem cells (MaSC) that are able to differentiate into the two primary epithelial cell lineages of normal mammary glands, i.e., luminal and myoepithelial cells [33-35]. Importantly, accumulating data indicate that Lgr5 marks cancer cells with tumor initiating capacity [36-38], which possess characteristics of cancer stem cells (CSCs). CSCs are tumor cells that can selfrenew and have clonal tumor initiating capacity alongside long-term repopulation potential to facilitate recurrence and metastasis. Experimental models and clinical studies have indicated that CSCs survive many conventional cancer therapeutics [39].

We hypothesize that LGR5, an established CSCs marker in several cancers including BC [40], can be used to identify at-risk $\mathrm{BC}$ patients that would benefit from treatment and can also serve as a therapeutic target for high-grade $\mathrm{ER}^{-} \mathrm{BC}$ lesions.

\section{Methods \\ DCIS TMA and BC TMA}

The BC tissue microarray (TMA) was generated from a consecutive series of tumors from patients diagnosed with primary invasive $\mathrm{BC}$ at the Department of Pathology, Malmö University Hospital between 1988 and 1992 with a median follow-up of 106 months. The cohort is described in detail elsewhere [41]. $\mathrm{ER}^{+}$was determined as over $10 \%$ positive cells, according to national guidelines. Of all 498 cases originally included in the TMA, only 401 could be annotated for LGR5 due to tumor loss or low tumor cell content. The mean and median age at diagnosis was 65 years, ranging from 28 to 96 years of age. Ethical permits were obtained from the ethical committee at Lund University.

The DCIS TMA included women from a populationbased cohort diagnosed with primary DCIS between 1986 and 2004 in two different Swedish counties and followed until November 2011. The cohort is described in detail elsewhere [42]. Due to either tumor loss or low tumor cell content, only 119 DCIS tumors (originally 480 cases) were annotated for LGR5. The mean age at diagnosis for these patients were 57 years, ranging from 30 to 90 years of age, with a median age of 58 years. $\mathrm{ER}^{+}$was determined as over $10 \%$ positive tumor cells, according to national guidelines. Ethical permits were obtained from the ethical committee at Uppsala University Hospital.

\section{Immunohistochemistry and annotation}

TMA sections mounted on glass slides were deparaffinized prior to antigen retrieval and stained with anti- 
LGR5 antibody (Abcam ab75732). The staining intensity of LGR5 was evaluated in tumor cells and scored from 0 to 3 with $0-1$ denoting low and 2-3 denoting high. The staining intensity was evaluated by $\mathrm{C} . \mathrm{H}$ and $\mathrm{C}$. L (Cohen's kappa, 0.41), blinded to all clinical information during scoring, first separately then interpretation combined.

\section{Cell lines}

For generation of the MDA-MB-231 LGR5 KD (MDALGR5KD) cell line viral production was carried out using TransIT-LT1 (Mirus Bio) mediated transfection of HEK293T cells. Virus was added to the cells with Polybrene and MDA-MB-231 (MDA-ctrl), a TNBC cell line, was transduced with pLKO.1-TRC containing shSCR or shLgr5 sequences [43]. Stably transduced cells were selected in puromycin for at least 5 days. Knockdown of Lgr5 was confirmed by qPCR. The MCF7 cell line, a Luminal A BC cell line, was used to compare TNBC to luminal BC. All cell lines were cultured in DMEM highglucose $+10 \%$ fetal bovine serum $+1 \%$ Penicillin Streptomycin. Cells were tested for Mycoplasma by PCR amplification using primers Myco+ (5'-GGG AGC AAA CAG GAT TAG ATA CCC T-3') and Myco- (5'-TGC ACC ATC TGT CAC TCT GTT AAC CTC-3') every 6 months and treated for a minimum of 2 weeks with Plasmocin (InvivoGen) if the Mycoplasma PCR was positive, until the PCR was negative.

\section{RNA extraction and real-time PCR}

Total RNA was extracted from the MDA-ctrl, MDALGR5KD, and MCF7 cell lines using the RNeasy kit (Qiagen). For total RNA extraction from wild-type, C3(1)-Tag, and MMTV-PyMT mammary glands/tumors, tumor bearing mice were staged according to wellknown time windows of hyperplasia, adenoma, and carcinoma [44, 45]. Mammary glands were surgically extracted, flash frozen, and pulverized. RNA extraction was performed using RNeasy kit. Reverse transcription was performed using iScript from Biorad. RNA quantity was analyzed with a NanoDrop spectrophotometer. Real-time PCR (rtPCR) was performed in a RealPlex2 (Eppendorf). Data was normalized to GAPDH for both human and mouse rtPCR analyses.

RT-PCR Primer List - Human

\begin{tabular}{|c|c|c|}
\hline Gene & Forward Primer $\left(5^{\prime}-->3^{\prime}\right)$ & Reverse Primer $\left(5^{\prime}-->3^{\prime}\right)$ \\
\hline Lgr5 & TCTTCACCTCCTACCTGGACCT & $\begin{array}{l}\text { GGCGTAGTCTGCTATGTG } \\
\text { GTGT }\end{array}$ \\
\hline yclin & ATGTTCGTGGCCTCTAAGATGA & CAGGTTCCACTTGAGCTTGTTC \\
\hline E-Myc & AAAGGCCCCCAAGGTAGTTA & GCACAAGAGTTCCGTAGCTG \\
\hline POH & AACGGGAAGCCCATCACC & CAGCCTTGGCAGCACCAGTGG \\
\hline
\end{tabular}

\section{Methods (Continued)}

ATCTT

RT-PCR Primer List - Mouse

Gene Forward Primer (5' -- > 3')

Lgr4 CCCGACTTCGCATTCACCAA

Lgr5 ACATTCCCAAGGGAGCGTTC ATGTGGTTGGCATCTAGGCG

Lgr6 ATCATGCTGTCCGCTGACTG ACTGAGGTCTAGGTAAGCCGT

GAPDH TGCACCACCAACTGCTTAG GGATGCAGGGATGATGTTC

\section{D colony forming assay}

3000 cells of MDA-ctrl or MDA-LGR5KD were seeded in $50 \mu \mathrm{l}$ of 1:1 Matrigel:medium (Gibco DMEM highglucose, 10\% fetal bovine serum, 1\% Penicillin Streptomycin) and plated onto 6-well plates. Cells were monitored for spheroid formation on days 1, 4 and 6.

\section{Cleared mammary fat pad transplantation of MDA-MB- 231 cell lines}

For mammary orthotopic transplants, $10^{6}$ tumor cells plus $10^{5}$ human cancer-associated fibroblasts (previously isolated [46] and immortalized utilizing insertion of hTERT into patient-derived fibroblasts [47, 48]) were injected in the right inguinal fat pad number 4 of SCID/ $\mathrm{NCr}$ mice on the BALB/c background (Charles River) in $50 \mu \mathrm{l}$ Matrigel. Tumor diameter was measured with calipers every week for 6 weeks. All procedures involving animals and their care were performed in accordance with the guidelines of the American Association for Accreditation for Laboratory Animal Care and the U.S. Public Health Service Policy on Human Care and Use of Laboratory Animals. All animal studies involving fat pad transplantation of MDA-MB-231 cell lines were approved and supervised by the Washington University Institutional Animal Care and Use Committee in accordance with the Animal Welfare Act, the Guide for the Care and Use of Laboratory Animals and NIH guidelines (Protocol 20,150,145).

\section{Cleared mammary fat pad transplantation of PDX and treatment with antibodies}

Patient derived xenograft (PDX) tumors were implanted as $\sim 8 \mathrm{~mm}^{3}$ fragments into the right inguinal fat pad of NOD/SCID mice between 4 and 6 weeks of age following established protocols [49]. Mice were monitored until the tumors reached $150-200 \mathrm{~mm}^{3}$ then intra-peritoneally injected with anti-LGR5-vc-MMAE antibody drug conjugate (ADC) [12 mg/kg] once/week for 4 weeks. Control mice were treated with anti-gDMC-vc-PAB-MMAE $(12 \mathrm{mg} / \mathrm{kg})$. Both control and experimental mice were also treated with gD-5237 (30 
$\mathrm{mg} / \mathrm{kg}$ ), a non-binding antibody control, $4 \mathrm{~h}$ prior to treatment with anti-LGR5 ADC. Mice were dissected 4 days following the last treatment. All animal experiments involving fat transplantation of PDX were reviewed and approved by the Institutional Animal Care and Use Committee (IACUC) at the University of California, San Francisco.

\section{Lineage tracing}

Lgr5-EGFP-IRES-creERT2/Rosa-Tomato/C3-Tag

mice were generated by crossing Lgr5-EGFP-IREScreERT2/Rosa-Tomato C57Bl/6 mice [36] with C3-Tag (1) FVB mice [50]. 7-week-old Lgr5-EGFP-IREScreERT2/Rosa-Tomato/C3-Tag (1) mice were treated with $5 \mathrm{mg}$ tamoxifen (Sigma cat\#T5648-1G) in $200 \mathrm{ul}$ sunflower seed oil (Sigma cat\#S5007-250ML) 3 times/ week for 1 week. Hyperplastic mammary glands were harvested and imaged for fluorescence on the Leica MZ16F stereoscope, 4 days following the end of treatment. All animal experiments involving lineage tracing were reviewed and approved by the Institutional Animal Care and Use Committee (IACUC) at the University of California, San Francisco.

\section{Bioinformatics and computational analysis of high- throughput data}

The clinical and gene expression data of $\mathrm{BC}$ from the METABRIC database were deposited in European Genotype Archive (http://www.ebi.ac.uk/ega/page.php according to the accession number: EGAS00000000083 and can be a.

Primary human breast cancer IHC: human LGR5

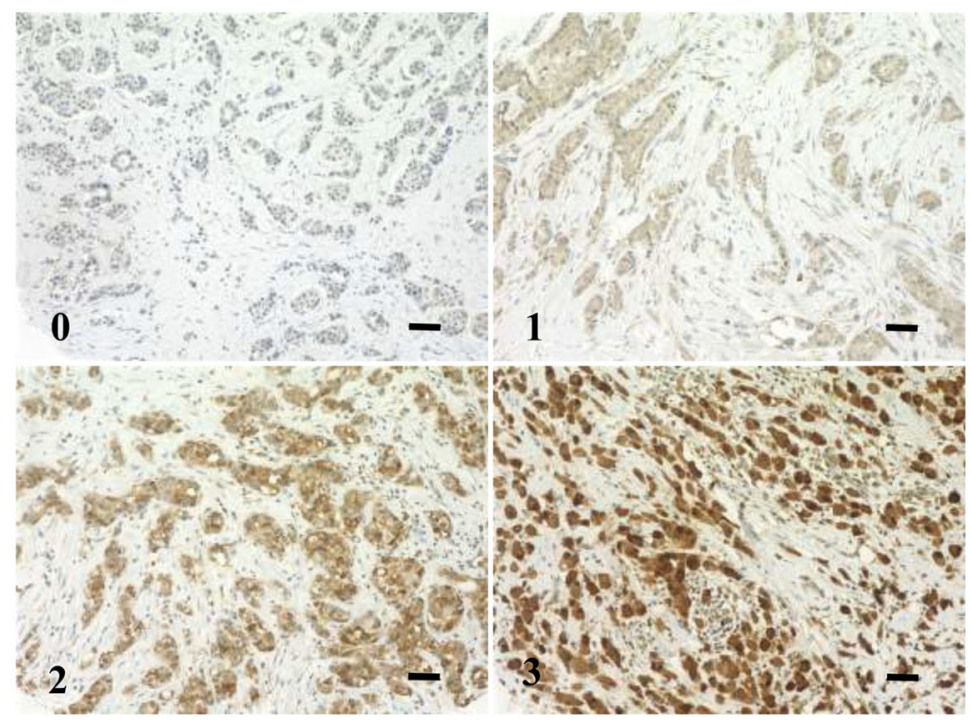

b.

LGR5 Expression in METABRIC

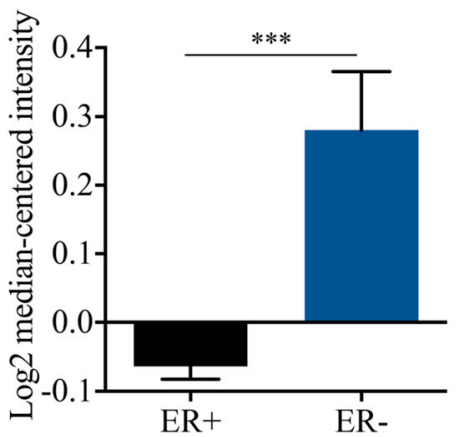

c.

LGR5 Expression in METABRIC database

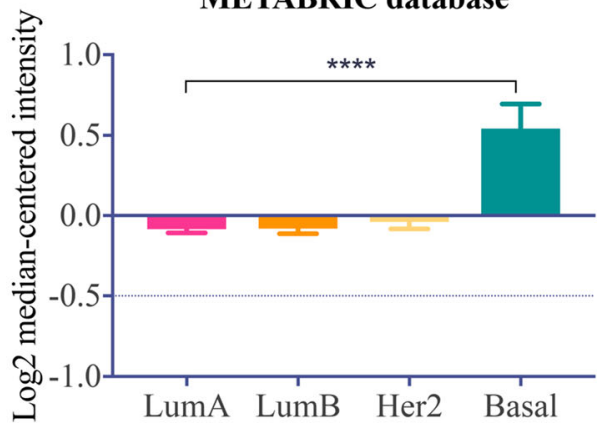

Fig. 1 LGR5 and clinicopathological features in BC. a Representative images of LGR5-stained primary human BC (numbers on bottom left of each image indicate score for tumor staining intensity). Scale bar, $50 \mu \mathrm{M}$. b Analysis of patient samples in METABRIC database for LGR5 expression in $>E R^{-}$vs. $E R^{+} B C$ show elevated $L G R 5$ expression in $E R^{-} B C$. $\mathbf{c}$ Various $B C$ subtypes with Basal $B C$ showing a statistically significant elevation in $L G R 5$ expression compared to Luminal A, Luminal B, and Her2, mean \pm SEM. (Student $t$-test, ${ }^{* * *} P<0.001,{ }^{* * *} P<0.0001$ ) 
downloaded from the Oncomine platform (www.oncomine. org) [51]. Statistical analysis of the differences in LGR5 transcript expression in different tissues were calculated by Oncomine standard algorithms: for each microarray, data were log2-transformed, median-centered, and normalized with standard deviation.

\section{Statistics}

GraphPad Prism7 was used to perform the statistical analysis. $P$ values were generated using the unpaired Student's t-test between two groups, whereas a one-way analysis of variance was employed to determine two or more group differences with Tukey's multiple comparisons. $P$-values $\leq 0.05$ were considered significant.

Spearman's Rho tests were used for correlation analysis and Kaplan-Meier analysis with log-rank test was used to depict differences in recurrence and death due to BC. Cox regression proportional hazards models were used for estimation of hazard ratios (HR) for recurrence and for death from breast cancer in both uni- and multivariable analysis. Covariates with a $P$ value $<0.05$ in the univariable analysis were included in the multivariable analysis. All statistical tests were two sided and $P$ value $\leq 0.05$ was considered significant. IBM SPSS Statistics version 24 was used to perform the analysis.

The remark criteria were used to report the data [52].

\section{Results}

\section{Clinical importance of LGR5 in BC and its prognostic value}

To decipher the role of LGR5 in BC we stained a BC TMA (Fig. 1a). LGR5 negatively correlated to tumor size $(P=0.001)$, nodal metastasis $(P=0.002)$, Nottingham histological grade $(\mathrm{NHG})(P=0.047)$ and ER $(P=0.001)$ (Table 1). Further investigation of BC patients included in the METABRIC database was in line with our data showing that LGR5 gene expression was significantly higher in $\mathrm{ER}^{-} \mathrm{BC}$ and basal subtypes (Fig. 1b-c).

Next, we evaluated the prognostic role of LGR5 for recurrence-free survival (RFS) among BC patients. Since we did not observe any overall prognostic significance of LGR5 in BC patients (Additional Fig. 1a-b), we stratified the analysis for $\mathrm{ER}^{-}$and $\mathrm{ER}^{+}$tumors. A total of $337 \mathrm{pa}-$ tients $(85 \%)$ had $\mathrm{ER}^{+}$tumors. LGR5 staining intensities were dichotomized into LGR $5^{\operatorname{low}(0+1)}$ and LGR5 $5^{\text {high }(2+3)}$. LGR $5^{\text {high }}$ patients accounted for $41.3 \%$ of all $\mathrm{ER}^{+} \mathrm{BC}$ patients and $36 \%(N=37)$ of these patients experienced recurrence during follow-up, whereas 56\% $(N=71)$ of the patients with LGR $5^{\text {low }}$ tumors recurred $(P=0.024$; Fig. 2a-b). Univariable cox regression analysis showed that $\mathrm{ER}^{+} \mathrm{LGR} 5^{\text {high }} \mathrm{BC}$ tumors had a statistically significant decrease in recurrence rate $[P=0.025, \mathrm{HR} 0.632$ (95\% CI, 0.42-0.95), (Additional Table 1)]. However, LGR5 was not an independent prognostic factor as
Table 1 Correlation between LGR5 expression and clinicopathologic features in primary breast cancer

\begin{tabular}{|c|c|c|c|c|c|c|c|}
\hline \multirow[t]{2}{*}{ Variable } & \multirow[t]{2}{*}{ Patients N (\%) } & \multicolumn{4}{|c|}{ LGR5 intensity } & \multirow[t]{2}{*}{ R } & \multirow[t]{2}{*}{$\boldsymbol{P}$ value } \\
\hline & & 0 & 1 & 2 & 3 & & \\
\hline All & $401(100)$ & 69 & 157 & 151 & 24 & & \\
\hline \multicolumn{8}{|l|}{ Age } \\
\hline$<50$ & $67(16.7)$ & 8 & 32 & 23 & 4 & -0.003 & \multirow[t]{2}{*}{0.95} \\
\hline$\geq 50$ & 334 (83.3) & 61 & 125 & 128 & 20 & & \\
\hline \multicolumn{8}{|l|}{ Tumor size } \\
\hline$\leq 20 \mathrm{~mm}$ & $232(57.9)$ & 32 & 82 & 104 & 14 & \multirow[t]{2}{*}{-0.162} & \multirow[t]{2}{*}{0.001} \\
\hline$>20 \mathrm{~mm}$ & $169(42.1)$ & 37 & 75 & 47 & 10 & & \\
\hline \multicolumn{8}{|l|}{ Ki67 } \\
\hline $0-10 \%$ & $139(36.4)$ & 27 & 48 & 57 & 7 & \multirow[t]{3}{*}{0.012} & \multirow[t]{3}{*}{0.81} \\
\hline $11-25 \%$ & $127(33.2)$ & 23 & 45 & 43 & 9 & & \\
\hline$>25 \%$ & $116(30.4)$ & 17 & 48 & 43 & 8 & & \\
\hline \multicolumn{8}{|l|}{ NHG } \\
\hline 1 & $93(23.3)$ & 13 & 31 & 44 & 5 & \multirow[t]{3}{*}{-0.100} & \multirow[t]{3}{*}{0.047} \\
\hline 2 & $161(40.3)$ & 30 & 58 & 63 & 10 & & \\
\hline 3 & $146(36.5)$ & 26 & 67 & 44 & 9 & & \\
\hline \multicolumn{8}{|c|}{ Nodal metastasis } \\
\hline No & $208(57.8)$ & 24 & 86 & 87 & 11 & \multirow[t]{2}{*}{-0.162} & \multirow[t]{2}{*}{0.002} \\
\hline Yes & $152(42.2)$ & 38 & 60 & 49 & 5 & & \\
\hline \multicolumn{8}{|l|}{ ER } \\
\hline$\leq 10 \%$ & $61(15.2)$ & 3 & 23 & 26 & 9 & \multirow[t]{2}{*}{-0.166} & \multirow[t]{2}{*}{0.001} \\
\hline$>10 \%$ & $340(84.4)$ & 66 & 134 & 125 & 15 & & \\
\hline \multicolumn{8}{|l|}{ PR } \\
\hline$\leq 10 \%$ & $125(31.2)$ & 20 & 45 & 48 & 12 & \multirow[t]{2}{*}{-0.70} & \multirow[t]{2}{*}{0.16} \\
\hline$>10 \%$ & $276(68.8)$ & 49 & 112 & 103 & 12 & & \\
\hline Luminal A & $214(53.6)$ & 41 & 87 & 77 & 9 & -0.092 & 0.065 \\
\hline Luminal B & $35(8.8)$ & 8 & 13 & 13 & 1 & -0.043 & 0.40 \\
\hline HER2 & $22(5.5)$ & 0 & 9 & 10 & 3 & 0.110 & 0.028 \\
\hline Basal & $136(34.3)$ & 15 & 55 & 55 & 11 & 0.103 & 0.040 \\
\hline
\end{tabular}

Abbreviations: LGR5 Leucine-rich repeat-containing G-protein coupled receptor $5, R$ correlation coefficient, NHG Nottingham histologic score, ER estrogen receptor, $P R$ progesterone receptor, $H E R 2$ human epidermal growth factor receptor. Spearman correlation, two-tailed- value. Bold indicates $P$-value $<0.05$

determined with multivariable cox regression analysis (Additional Table 1).

We then evaluated the prognostic value of LGR5 in $\mathrm{ER}^{-} \mathrm{BC}$. We found that LGR5 had a prognostic significance for high-grade $\mathrm{ER}^{-} \mathrm{BC}$ patients only (Fig. 2c-f and Additional Fig. 1c-d). High-grade ER ${ }^{-}$BC patients with LGR $5^{\text {high }}$ tumors more frequently experienced recurrence $(P=0.008)$ and death due to $\mathrm{BC}$ $(P=0.009)$. Univariable cox regression analysis showed that high-grade $E R^{-} L G R 5^{\text {high }}$ BC tumors had a 
a.

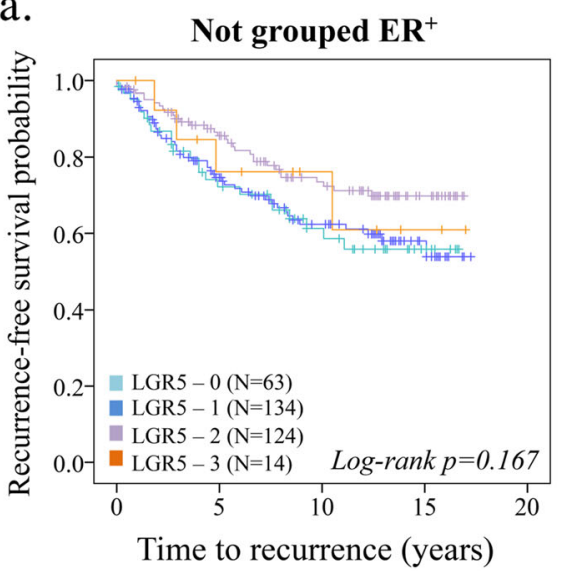

c.

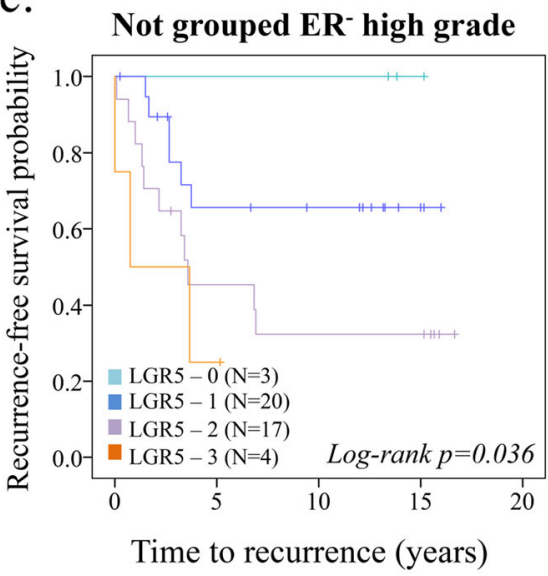

e.
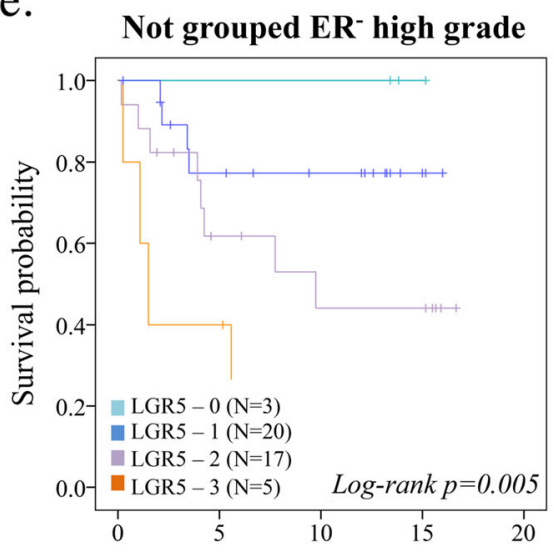

Time to death due to $\mathrm{BC}$ (years) b.

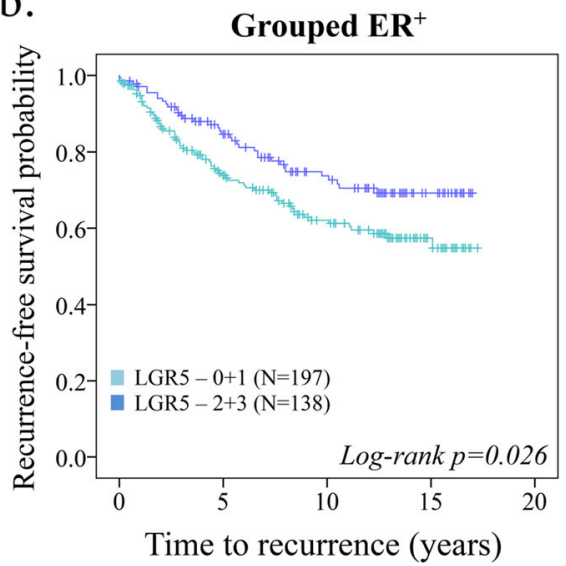

d.
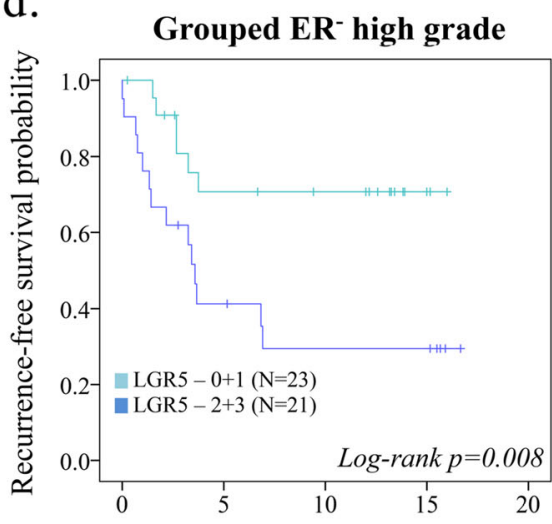

Time to recurrence (years)

f.

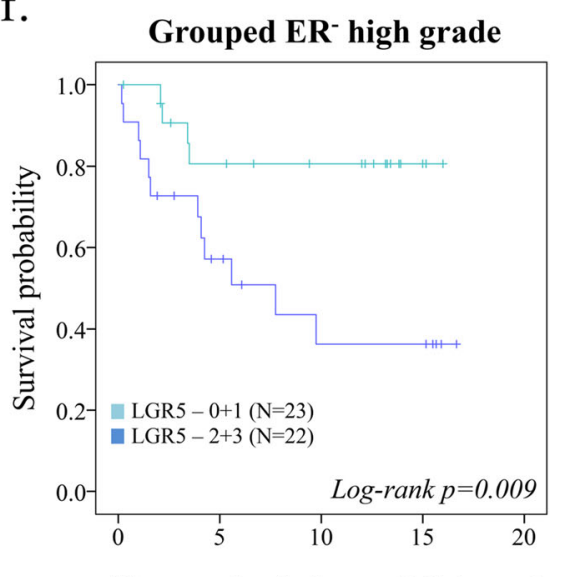

Time to death due to BC (years)

Fig. 2 Prognostic impact of LGR5 in $E R^{+}$vs. ER ${ }^{-}$BC. a Kaplan-Meier plots (log-rank test) displaying recurrence-free survival according to LGR5 in $\mathrm{ER}^{+} \mathrm{BC}$ not-grouped and $\mathbf{b} L \mathrm{LGR} 5$ dichotomized into LGR5 ${ }^{\text {low }}{ }^{(0-1)}$ and LGR5 $5^{\text {int/high (2-3) }}$ tumor staining intensity. $\mathbf{c}$ Kaplan-Meier plots (log-rank test) displaying recurrence-free survival according to LGR5 in high-grade ER ${ }^{-} B C$ not-grouped and $\mathbf{d}$ LGR5 dichotomized into LGR5 ${ }^{\text {low }}(0-1)$ and LGR5 $5^{\text {int/high (2-3) }}$ tumor staining intensity. e Kaplan-Meier plots (log-rank test) displaying BC-specific survival according to LGR5 in high-grade ER ${ }^{-}$ BC not-grouped or $\mathbf{f}$ Dichotomized into LGR5 ${ }^{\text {low }(0-1)}$ and LGR5 $5^{\text {inthigh }}{ }^{(2-3)}$ tumor staining intensity 
statistically significant increase in recurrence rate $[P=$ 0.013, HR 3.36 (95\% CI, 1.29-8.77)] (Additional Table 2) and death due to $\mathrm{BC}[P=0.016$, HR 4.03 (95\% CI, 1.2912.55)] (Additional Table 3). LGR5 was a borderline independent prognostic factor as determined with multivariable cox regression analysis for recurrence $[P=$ 0.065, HR 2.64 (95\% CI, 0.94-7.43)] (Additional Table 2) and death due to $\mathrm{BC}[P=0.075$, HR 3.08 (95\% CI, 0.8910.60)] (Additional Table 3).

\section{Clinical importance of LGR5 in DCIS and its prognostic value}

To further explore the importance of LGR5 in BC initiation and its clinical importance, we analyzed correlations between various clinicopathological features and LGR5 protein expression in DCIS (Fig. 3a). While there was no significant correlation to age, proliferation, nuclear grade, ER or PR, LGR5 expression correlated with tumor size $[P=0.01]$ (Table 2 ).

Among the 119 patients for whom LGR5 staining was performed, 7 women died due to $\mathrm{BC}$ during the 169 months follow-up. All of the women who later died of BC had LGR5-positive (LGR5 $5^{\text {int/high(1-3) }}$ ) DCIS tumors, while none of the women with LGR $5^{\text {low(0) }}$ experienced BC-related death, accounting for $32 \%$ of all DCIS patients (Fig. 3b-c). The potential of LGR5 as a prognostic biomarker appeared to be independent of the ER status of the DCIS tumors (Additional Fig. 2a-b). Of note, there was no major difference in the distribution of in situ or invasive relapse between LGR $5^{0}$ and LGR $5^{1-3}$ DCIS tumors (Additional Fig. 2c).

\section{The tumorigenic role of LGR5 in $\mathrm{ER}^{-} \mathrm{BC}$}

To further assess the importance of LGR5 in highgrade $\mathrm{ER}^{-} \mathrm{BC}$, and specifically, whether LGR5 could

a.

Primary human breast DCIS IHC: human LGR5

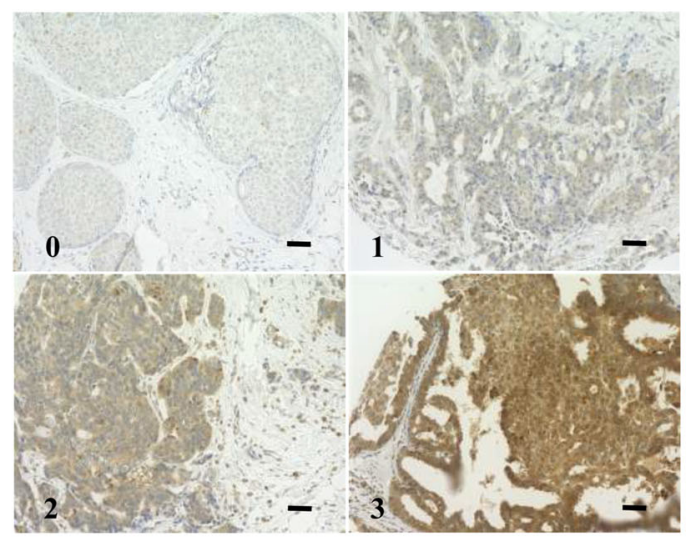

b.

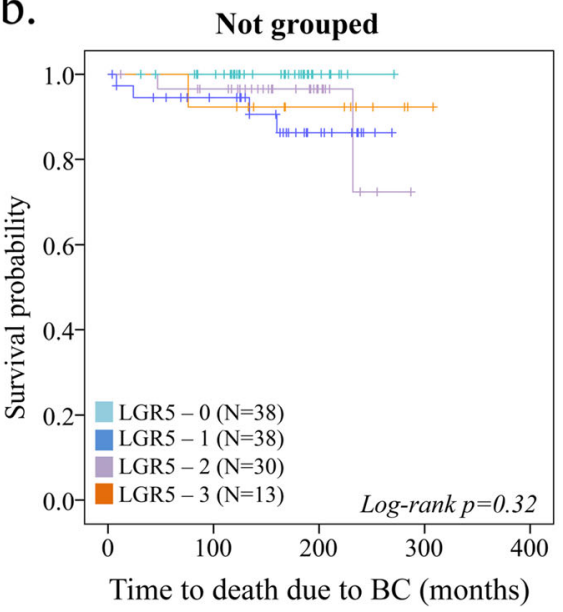

c.

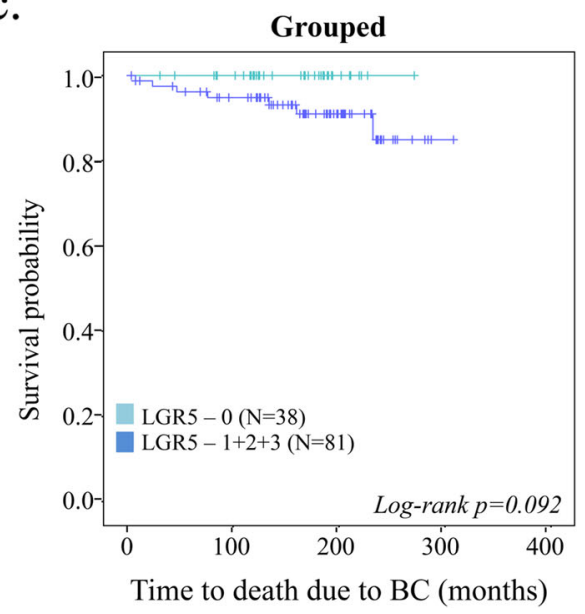

Fig. 3 Clinical importance of LGR5 in DCIS and its prognostic value. a Representative images of LGR5-stained primary human DCIS tumors (numbers on bottom left of each image indicate score for tumor staining intensity). Scale bar, 50 MM. b Kaplan-Meier plots (log-rank test) displaying time to death due to BC according to LGR5 staining intensity not-grouped or c LGR5 dichotomized into LGR5 ${ }^{\text {low }(0)}$ and LGR5 $5^{\text {int/high }}(1+2+3)$ tumor staining intensity 
Table 2 Correlation between LGR5 expression and clinicopathologic features in DCIS

\begin{tabular}{|c|c|c|c|c|c|c|c|}
\hline \multirow[t]{2}{*}{ Variable } & \multirow[t]{2}{*}{ Patients N (\%) } & \multicolumn{4}{|c|}{ LGR5 intensity } & \multirow[t]{2}{*}{ R } & \multirow[t]{2}{*}{$\boldsymbol{P}$ value } \\
\hline & & $\overline{0}$ & 1 & 2 & 3 & & \\
\hline All & $119(100)$ & 38 & 38 & 30 & 13 & & \\
\hline \multicolumn{8}{|l|}{ Age } \\
\hline$<50$ & 38 (31.9) & 13 & 11 & 11 & 3 & 0.027 & 0.77 \\
\hline$\geq 50$ & $81(68.1)$ & 25 & 27 & 19 & 10 & & \\
\hline \multicolumn{8}{|l|}{ Tumor size } \\
\hline$\leq 20 \mathrm{~mm}$ & $73(76)$ & 29 & 24 & 14 & 6 & 0.26 & 0.01 \\
\hline$>20 \mathrm{~mm}$ & $23(24)$ & 3 & 8 & 9 & 3 & & \\
\hline \multicolumn{8}{|l|}{ Proliferation } \\
\hline$<10 \%$ & $60(57.1)$ & 19 & 15 & 16 & 10 & -0.046 & 0.63 \\
\hline$\geq 10 \%$ & 45 (42.9) & 10 & 20 & 13 & 2 & & \\
\hline \multicolumn{8}{|c|}{ Nuclear grade } \\
\hline 1 & $11(9.2)$ & 6 & 3 & 1 & 1 & 0.081 & 0.38 \\
\hline 2 & $46(38.7)$ & 14 & 14 & 13 & 5 & & \\
\hline 3 & $62(52.1)$ & 18 & 21 & 16 & 7 & & \\
\hline \multicolumn{8}{|l|}{ ER } \\
\hline$\leq 10 \%$ & $33(29.5)$ & 8 & 9 & 11 & 5 & -0.163 & 0.085 \\
\hline$>10 \%$ & 79 (70.5) & 28 & 27 & 17 & 7 & & \\
\hline \multicolumn{8}{|l|}{$P R$} \\
\hline$\leq 10 \%$ & $52(46.8)$ & 15 & 15 & 16 & 6 & -0.086 & 0.37 \\
\hline$>10 \%$ & $59(53.2)$ & 20 & 20 & 13 & 6 & & \\
\hline
\end{tabular}

Abbreviations: LGR5 Leucine-rich repeat-containing G-protein coupled receptor $5, R$ correlation coefficient, $E R$ estrogen receptor, $P R$ progesterone receptor; Proliferation by $\mathrm{IH}$ or S-phase Spearman correlation, two-tailed $P$-value. Bold indicates $P$-value $<0.05$

serve as a therapeutic target for this particular patient group, we turned to in vitro and in vivo studies. Using the ER ${ }^{-}$MDA-MB-231 (MDA-ctrl) cell line, a TNBC cell line, to knockdown (KD) LGR5 expression with siRNA (MDA-LGR5KD), we noticed a decrease in LGR5-associated genes, e.g., genes part of the canonical Wnt pathway [ $\beta$-catenin and cyclin D] (Fig. 4a, Additional Fig. 3a). The association of LGR5 with Wnt pathway genes, in particular $\beta$-catenin, was previously shown to be important in TNBC utilizing the MDA-MB-231 and MDA-MB-453 cell lines [53, 54]. To investigate the importance of LGR5 in colony-formation that evaluates tumor-initiating capacity, we performed an in vitro sphere assay using MDA-ctrl and MDA-LGR5KD cells. MDA-LGR5KD cells exhibited significant reduction in their ability to form spheres (Fig. 4b). In vivo studies with these cells further confirmed that MDA-LGR5KD cells form smaller tumors as measured by both size and weight (Fig. 4c-d). These data are in line with a previous publication [37].

\section{Targeting LGR5+ cells in $\mathrm{ER}^{-} \mathrm{BC}$ due to their tumor- initiating capacity}

Our DCIS TMA-derived data suggested a role for LGR5 in tumor initiation of BC with less favorable outcome. Gene expression analysis for Lgr5 across various stages of tumorigenesis in C3-(1) Tag ER and MMTV-PyMT $\mathrm{ER}^{+}$mouse models showed that C3-(1) Tag mice had upregulated expression of Lgr5 at the hyperplastic stage whereas $M M T V-P y M T$ showed no increase (Fig. 5a). Thus, using the C3(1) Tag $\mathrm{ER}^{-} \mathrm{BC}$ mouse model, which develops primary tumors following $\mathrm{BC}$ progression characteristic of human $\mathrm{BC}[44,50]$, we sought to further investigate the tumor-initiating capacity of $\mathrm{LgrS}^{+}$cells. To determine whether $\mathrm{LgrS}^{+}$cells possess tumor-initiating cells and whether they can generate progeny within hyperplastic lesions, we utilized tamoxifen-induced lineagetracing in triple-transgenic C3(1) Tag;Lgr5-EGFP; Rosa $^{\text {Tomato }}$ mice (Fig. 5b). Intriguingly, lineage tracing demonstrated that $\operatorname{Lgr5}^{+}$cell progeny generated the bulk of hyperplastic mammary tumors (Fig. 5b). All hyperplastic foci within the tamoxifen-induced tripletransgenic mice exhibited red fluorescence, denoting the tumor-initiating capacity of $\operatorname{Lgr~}^{+}$cells. Taken together, these data suggest a role for $\operatorname{LgrS}^{+}$cells as tumor-initiating cells in $\mathrm{ER}^{-} \mathrm{BC}$.

Given that LGR5 appears to have an important role in tumor initiation and progression of $\mathrm{ER}^{-} \mathrm{BC}$, we explored the ability to target LGR5 therapeutically. To recapitulate human $\mathrm{BC}$, we took advantage of an $\mathrm{ER}^{-} \mathrm{BC}$ PDX model. The PDX model is an attractive preclinical model to evaluate novel therapeutic alternatives since it harbors the malignant characteristics of tumors excised from BC patients, such as aberrations in copy number variations, epithelial-to-mesenchymal genes, and ER, PR, and HER2 expression [55]. We orthotopically transplanted the LGR5-expressing $\mathrm{ER}^{-} \mathrm{BC}$ PDX line HCI-001 in NOD/ SCID mice (Additional Fig. $3 \mathrm{~b}$ ) as previously described $[38,49]$. Once tumors reached $150-200 \mathrm{~mm}^{3}$, we treated the mice with anti-LGR5 (hu8E11v2)-MC-vc-PABMMAE, a well-characterized antibody-drug conjugate (ADC) targeting LGR5 with minimal side-effects in mice such as minor weight loss [56]. Following 2 weeks of treatment, anti-LGR5-ADC treated tumors stopped growing and then significantly reduced in size while the control tumors continued to grow (Fig. $5 \mathrm{c}$-d).

In their totality, our data indicate the potential role of LGR5 both as a prognostic tool to determine malignant DCIS lesions alongside the value of utilizing LGR5 to stratify $\mathrm{ER}^{+}$and $\mathrm{ER}^{-} \mathrm{BC}$ tumor grade and recurrence (Fig. 6). The interrogation of clinical samples alongside in vitro and in vivo experiments in transgenic and PDX mouse models of $\mathrm{BC}$ demonstrates the potential of therapeutic intervention for TNBC patients by 


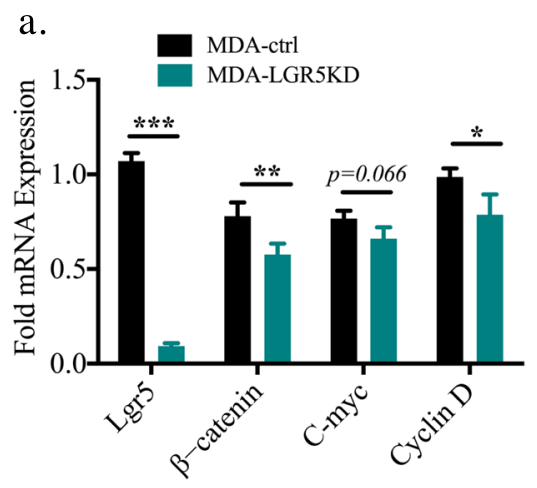

c.

MDA-MB-231

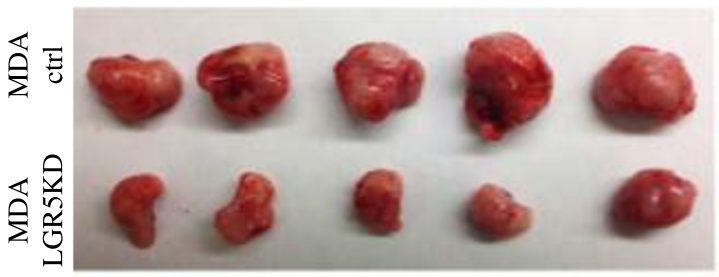

b.

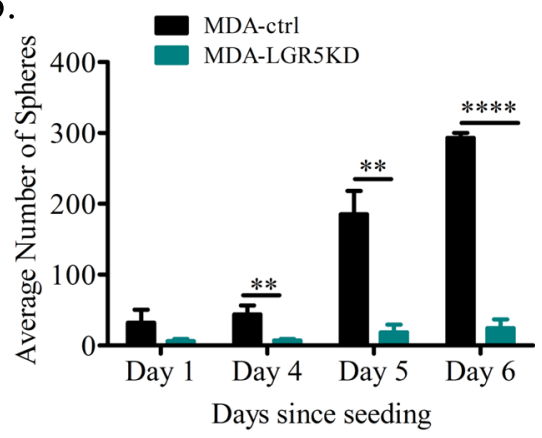

d.

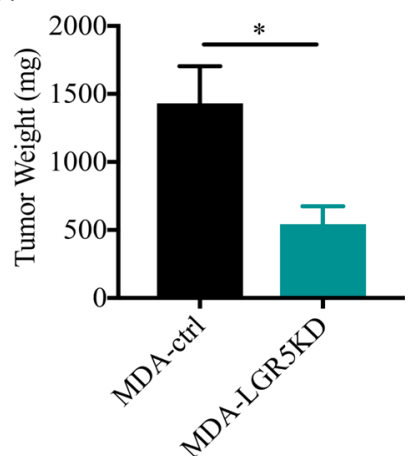

Fig. 4 The tumorigenic role of LGR5 in ER ${ }^{-} B C$. a Gene expression profiles in control and LGR5-KD MDA-MB-231 (MDA) cell lines. KD of LGR5 downregulates canonical Wht pathway genes, such as $\beta$-catenin and Cyclin $D\left(n=3\right.$, Mean \pm SD, Student $t$-test, $\left.{ }^{* *} P<0.01,{ }^{* * * P}<0.001\right)$. b Colony assay as a surrogate for tumor initiating capacity using single MDA-ctrl and MDA-LGR5KD cells in 3D culture showing number of spheres across increasing days in culture. KD of LGR5 significantly reduces sphere formation when compared to MDA-ctrl $\left(n=3\right.$, Mean $\pm S D$, Student $t$-test, ${ }^{*} P<$ $\left.0.05,{ }^{* * P}<0.01,{ }^{* * *} \mathrm{P}<0.0001\right)$. c Representative images from resected tumors of $1 \times 10^{6} \mathrm{MDA}$ cells transplanted in Matrigel that were allowed to grow in the inguinal mammary gland for 6 weeks. $\mathbf{d}$ Weights of resected tumors from MDA-ctrl $(n=4)$ and MDA-LGR5KD cell lines ( $n=4)$ shows that KD of LGR5 attenuates tumor growth. Mean \pm SD. (Student $t$-test, ${ }^{*} P<0.05$ )

specifically targeting the tumorigenic $\mathrm{LGR}^{+}$tumor initiating cells.

\section{Discussion}

The value of this study is several fold: First, we demonstrate an important differential prognostic value for LGR5 in $\mathrm{ER}^{+}$vs. $\mathrm{ER}^{-} \mathrm{BC}$. Next, we showed evidence that LGR5 can help discern DCIS lesions that will become metastatic from those that will not progress into a fatal disease. Lastly, we performed in vitro and in vivo studies in various mouse models of $\mathrm{BC}$ to further substantiate a role for LGR5 in tumor initiation and solidify LGR5 as a valid therapeutic target for TNBC.

To date, the clinical importance of LGR5 for BC remains largely unexplored outside of two clinical studies that have correlated LGR5 with TNBC [37] and with tumor size and lymph node metastasis [57]. However, these studies did not determine the prognostic impact of LGR5 expression in $\mathrm{ER}^{+}$vs. $\mathrm{ER}^{-}$tumors separately. We have done so in the study described here, offering an explanation as to why some previous data appear contradictory to data presented here. In the study by Yang et al. the majority of patients (62\%) had $\mathrm{ER}^{-}$tumors [37], while clinically approximately $80 \%$ of all $\mathrm{BC}$ tumors are $\mathrm{ER}^{+}$with considerably better outcomes compared to $\mathrm{ER}^{-} \mathrm{BC}[6,58]$. In our BC TMA, $85 \%$ of the patients had $\mathrm{ER}^{+}$tumors and our data pointed to distinct roles for LGR5 in $\mathrm{ER}^{+}$vs. $\mathrm{ER}^{-} \mathrm{BC}$, presenting as a favorable variable for $\mathrm{ER}^{+}$patients but unfavorable for high grade $\mathrm{ER}^{-}$patients. The differential findings regarding the manifold roles of LGR5 in $\mathrm{ER}^{+}$vs. $\mathrm{ER}^{-} \mathrm{BC}$ might be partly explained by proliferative, estrogen-responsive $\mathrm{Lgr}^{+}$mammary cells [59] and a subset of dormant Lgr $5^{+}$Tetraspanin8 high (Tspan 8 hi MaSC responsive to ovarian hormones [60]. Lgr $5^{+}$Tspan 8 hi MaSC, which are more quiescent as compared to $\mathrm{Lgr}^{+} \mathrm{Tspan} 8^{-} \mathrm{MaSC}$, may give rise to tumors that are distinct from those arising from the Lgr $5^{+}$Tspan $8^{-}$MaSC pool with regards to ER status.

Furthermore, prevailing data indicate that BC tumors originate from non-invasive tumors, i.e., in situ carcinomas [61]. While not all in situ carcinoma tumors will progress into invasive tumors and not all invasive tumors will gain metastatic ability, some DCIS will gain 
a. C3(1)-Tag TNBC

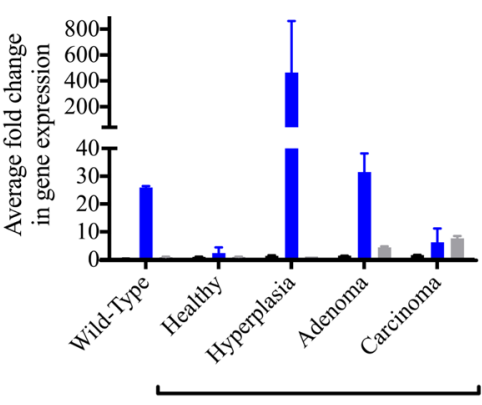

C3(1)-Tag
MMTV-PyMT Luminal B

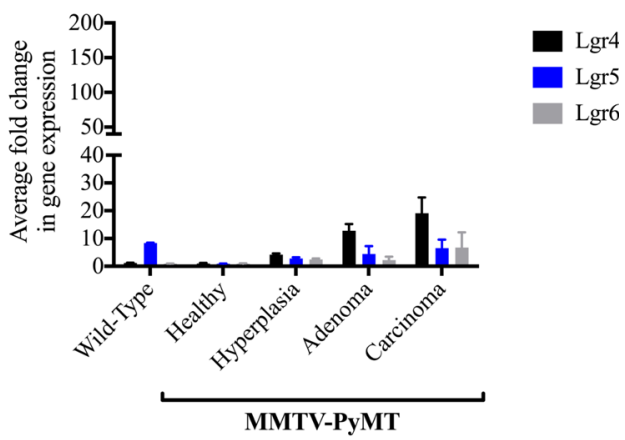

b.

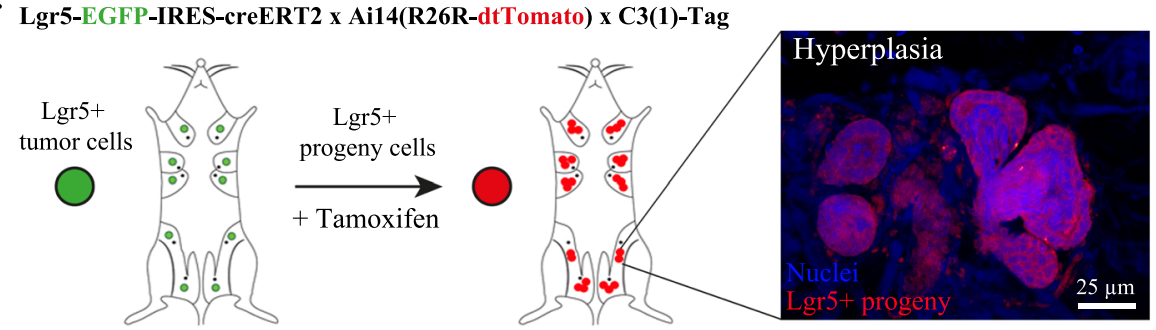

c.

PDX model HCI-001

d.

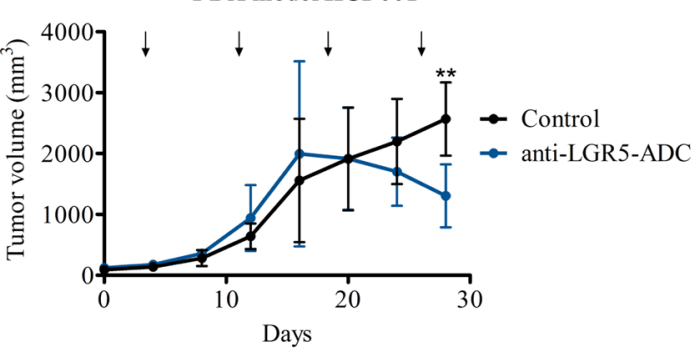

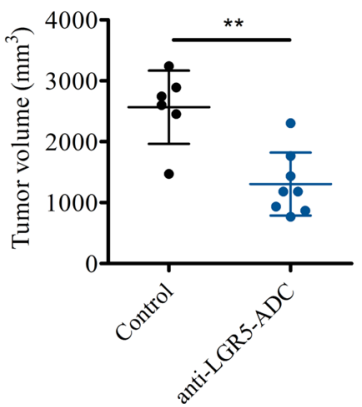

Fig. 5 Targeting LGR5+ cells in ER ${ }^{-} B C$ due to their tumor-initiating capacity. a Quantitative polymerase chain reaction for gene expression analysis of Lgr4, Lgr5, and Lgr6 in the C3(1)-Tag TNBC spontaneous BC mouse model and MMTV-PyMT Luminal B spontaneous BC mouse model. C3(1)-Tag mice have a greater fold-change in Lgr5 gene expression at hyperplasia as compared to other tumorigenic stages and also $\sim 20$-fold greater $L$ gr 5 expression level as compared to MMTV-PyMT hyperplasic foci. No major differences denoted in either Lgr4 or Lgr6 across tumorigenic stages and BC subtypes. ( $n=1$ with 3 replicates for WT, all C3(1)-Tag, and healthy MMTV-PyMT; $n=2$ MMTV-PyMT for Lgr4, Lgr6, and Lgr5 carcinoma, $n=4$ MMTV-PyMT for Lgr5 hyperplasia and adenoma) b Tamoxifen (Tam)-induced Cre recombinase knocked into the Lgr5 locus, Lgr5-EGFP-IRES-creERT2 crossed to Tomato reporter mice, Ai14(R26R dtTomato) indicated Lgr5 ${ }^{+}$cell progeny in hyperplasias (whole mounts, 1-week Tam treatment, 3 times/week) of the C3(1) Tag mouse model of TNBC. c Tumor volumes during treatment of LGR5-expressing TNBC PDX model mice over 4-weeks with anti-LGR5 (hu8E11V2)MC-vc-PAB-MMAE (anti-LGR5-ADC, $n=8$ ) and anti-gD-MC-vc-PAB-MMAE (Control $n=6$ ). Arrow indicate administration of antibodies. $\mathbf{d}$ Tumor volumes of control mice and mice 4 weeks post treatment with anti-LGR5-ADC shows statistically significant decrease in overall tumor volume following inhibition of LGR5. Mean \pm SD. (Student $t$-test, ${ }^{* *} \mathrm{P}<0.01$ )

the ability for invasion and metastatic advancement. In this study, our DCIS TMA-derived data illustrate the value of utilizing LGR5 as a prognostic marker for DCIS tumors that have the potential to advance into fatal BC. Notably, all of the DCIS patients included in our cohort (independent of ER status) who later died due to BC had LGR $5^{1-3}$ DCIS tumors, while none of the patients with LGR5 ${ }^{0}$ succumbed to BC. Hence, LGR5 expression may specifically associate with DCIS tumors that have the potential to advance into fatal BC (Fig. 6). Future studies with a larger cohort of DCIS patients are needed to further validate our findings and the prognostic impact of LGR5 for DCIS patients. While we did not determine the ER status of the recurred BC tumors from the DCIS patients, it would be valuable to know whether the patients with $\mathrm{ER}^{+}$DCIS tumors, who later died due to $\mathrm{BC}$, had $\mathrm{ER}^{+}$or $\mathrm{ER}^{-} \mathrm{BC}$. Although $\mathrm{ER}^{-} \mathrm{DCIS}$ never progress into $\mathrm{ER}^{+} \mathrm{BC}, \mathrm{ER}^{+} \mathrm{DCIS}$ tumors can give rise to both $\mathrm{ER}^{+}$and $\mathrm{ER}^{-} \mathrm{BC}$ [62]. Our data could suggest that this may be partly attributed 


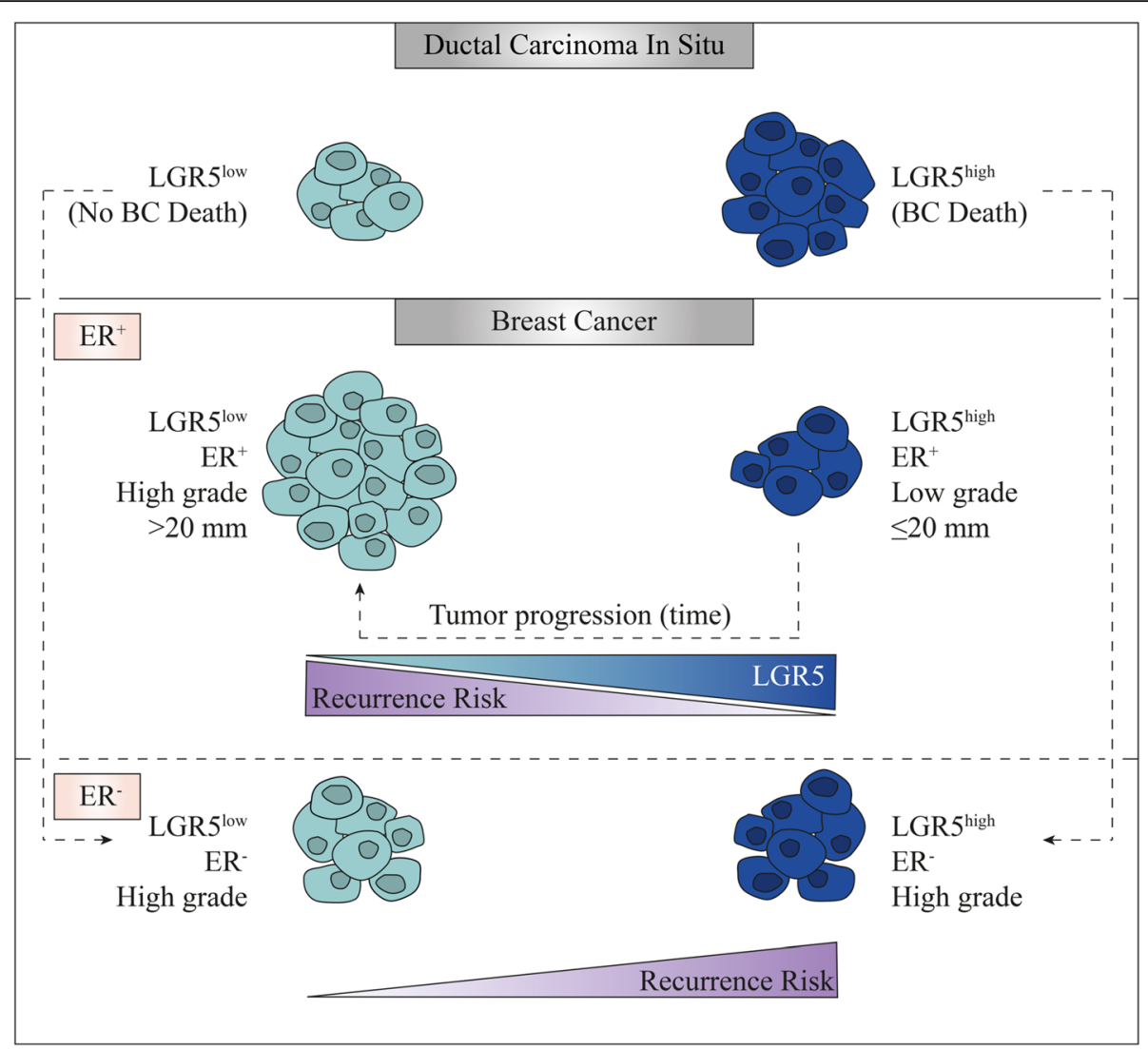

Fig. 6 Schematic illustration of the prognostic value of $L G R 5$ in $E R^{-}$vs. ER ${ }^{+} B C$. Both $L G R 5^{\text {low }}$ and $L G R 5^{\text {high }}$ DCIS tumors can progress into BC, however only LGR5 ${ }^{\text {high }}$ DCIS tumors progress into invasive tumors (possibly high-grade $L G R 5^{\text {high }} E R^{-}$) with related $B C$ death. $E R^{+} B C$ expressing high levels of LGR5 have a lower risk of recurrence, are smaller in size and of lower grade whereas $E R^{+} B C$ expressing low levels of LGR5 have a higher risk of recurrence, are larger in size and of higher grade. It could be that as $E R^{+}$tumors progress, they become larger in size, of higher grade and lose their LGR5 expression. In stark contrast, high grade ER ${ }^{-}$BC tumors with higher LGR5 expression stratifies a significantly greater recurrence rate as compared to tumors with lower LGR5 levels

to the high expression of LGR5 and its association with DCIS tumors that will later progress into fatal high-grade $\mathrm{ER}^{-} \mathrm{BC}$.

Patients with high-grade $\mathrm{ER}^{-} \mathrm{BC}$ generally have a poor prognosis with increased risk of recurrence and metastatic advancement. Here we show that LGR5 successfully differentiate patients within this $\mathrm{BC}$ subgroup with significantly lower risk of recurrence and death due to $\mathrm{BC}$ i.e. patients with LGR $5^{\text {low }}$ tumors. This furthermore supports a role for LGR5, not only in tumor-initiation, but also for metastatic progression. Indeed, the critically important clinical issue in BC, as in many cancers, is metastasis. These are initiated by specialized cancer cells that bear a tumor-initiating capacity. To establish LGR5 as a valuable therapeutic target, we assessed and substantiated a role for $\mathrm{LGR}^{+}$cells in tumor initiation. In vivo studies performed by other groups and confirmed by us, have shown that LGR5 ${ }^{+} \mathrm{ER}^{-} \mathrm{BC}$ cells bear an enhanced tumor-initiating capacity [37, 38]. In particular, we have done extensive work to prove the regenerative capabilities of $\mathrm{LGR}^{+}$cells [33]. Here we further substantiated a role for LGR5 in tumor initiation in TNBC by utilizing a lineage-tracing experiment in an autochthonous mouse model with high expression of LGR5 in hyperplastic $\mathrm{ER}^{-} \mathrm{TNBC}$. Based on this finding, we further revealed a therapeutic potential of anti-LGR5-ADC to target $\mathrm{LGR}^{+}$cells in aggressive $\mathrm{ER}^{-} \mathrm{BC}$. We showed that tumor growth is significantly attenuated upon administration of anti-LGR5-ADC using a human-inmouse PDX model expressing elevated levels of LGR5. The utilization of anti-LGR5-ADC to target a smaller subset of potentially quiescent, tumorigenic $\mathrm{LGR}^{+}$ tumor-initiating cells, which presumably are responsible for recurrence and metastatic progression [38, 63], presents a novel line of therapy for high-grade $\mathrm{ER}^{-}$ LGR5 ${ }^{\text {high }}$ BC. Anti-LGR5-ADC therapy can help enhance the therapeutic potential of conventional chemotherapy that targets the bulk of proliferating $\mathrm{BC}$ cells [39]. Anti-LGR5-ADC therapy is also a logical combination with the newly approved Tecentriq-Abraxane 
combo, which enhances $\mathrm{CD}^{+} \mathrm{T}$ cell killing through inhibiting PD-L1 [27], to heighten complete tumor regression along with durable responses in the deadly high-grade ER ${ }^{-}$LGR $5^{\text {high }}$ BC. Beyond LGR5's value as a prognostic marker, in a therapeutic scenario LGR5 can be utilized as a potential patient stratification tool.

\section{Conclusions}

We showed that LGR5 expression could potentially assist in preventing overtreatment by distinguishing indolent DCIS tumors from those that might progress into lethal BC. LGR5 expression can also be used to recognize high-grade $\mathrm{ER}^{-} \mathrm{BC}$ tumors with increased risk of recurrence and death due to $\mathrm{BC}$, a prognostic criterion that would enhance clinical $\mathrm{BC}$ diagnosis. Furthermore, we demonstrated proof-of-concept feasibility in using anti-LGR5-ADC as a novel therapeutic alternative for TNBC patients that could potentially be combined with currently approved checkpoint inhibitor combination for TNBC to promote durable complete response. Taken together, our data illustrates the clinical potential of using LGR5 as a diagnostic and prognostic biomarker as well as a therapeutic target in high grade $\mathrm{ER}^{-} \mathrm{BC}$.

\section{Supplementary information}

Supplementary information accompanies this paper at https://doi.org/10. 1186/s12885-020-06986-z.

Additional file(s): Figure 1. Prognostic role of LGR5 in BC. KaplanMeier plots (log-rank test) displaying recurrence-free survival according to LGR5 levels in BC TMA. A. Not-grouped and b. Dichotomized into LGR5 ${ }^{\text {low }}(0-1)$ and LGR5 $5^{\text {high }}{ }^{(2-3)}$ tumor staining intensity. Kaplan-Meier plot (log-rank test) displaying $\mathbf{c}$. recurrence free survival, and $\mathbf{d}$. death due to $B C$, in low-grade $E R^{-} B C$ according to LGR5 dichotomized into LGR5 ${ }^{\text {low }}$ ${ }^{(0-1)}$ and LGR5 int/high (2-3) tumor staining intensity. Figure 2. Prognostic role of LGR5 in DCIS according to ER status. Kaplan-Meier plots (log-rank test) displaying time to death due to BC according to LGR5 dichotomized into LGR5 ${ }^{\text {low }}{ }^{(0)}$ and LGR5 $5^{\text {int/high }}(1-3)$ tumor staining intensity in $\mathbf{a}$. ER $\mathrm{DCIS}$ and $\mathbf{b}$. $\mathrm{ER}^{+} \mathrm{DCIS}$. c. Distribution of No recurrences, In situ or Invasive recurrence in LGR5-DCIS subgroups (numbers 0,1-3 indicate tumor staining intensity). Figure 3. Gene expression analysis of Lgr4, Lgr5, and Lgr6. a. Quantitative polymerase chain reaction on human BC cell lines examining $L g r 4,5$, and 6 gene expression levels. Efficient knockdown of LGR5 alongside higher levels of canonical LGR5 in TNBC as compared to Luminal A BC. b. Analysis of publicly available microarray data of PDX models (accession number GSE32531) identifies Lgr5 as highly expressed in $\mathrm{HCl}-001$ xenograft 5th generation. $\mathrm{HCl}-001$ xenograft 5th generation was used in transplant experiments within NOD/SCID mice followed with anti-LGR5-ADC treatment. Table 1. Cox regression analyses for recurrence free survival in women with ER+ primary breast cancer. Table $\mathbf{2}$. Cox regression analyses for recurrence free survival (RFS) in women with high-grade ER- primary breast cancer. Table 3. Cox regression analyses for breast cancer specific survival (BCSS) in women with high-grade ERprimary breast cancer.

\section{Abbreviations}

DCIS: Ductal carcinoma in situ; ER: Estrogen receptor; BC: Breast cancer; HER2: Human epidermal growth factor receptor 2; TNBC: Triple negative breast cancer; PR: Progesterone receptor; LGR5: Leucine-rich repeat containing G-protein-coupled receptor 5; MaSC: Mammary stem cell; CSC: Cancer stem cells; TMA: Tissue microarray; PDX: Patient-derived xenograft; ADC: Antibody drug conjugate (ADC); KD: Knockdown;
IHC: Immunohistochemistry; rtPCR: Reverse transcription polymerase chain reaction

\section{Acknowledgements}

We thank Dr. Melissa Junttila for the anti-LGR5 (hu8E11v2)-MC-vc-PAB-MMAE and related reagents to this antibody. We also thank Björn Nodin for immunohistochemical staining of the DCIS and BC. We thank Helene Jacobsson, a medical statistician, for conducting the data and statistical tests on our clinical datasets. We also thank Elena Atamaniuc, Shaili Patel, Evelyn Sandoval and Maha Siddiqui for animal husbandry and genotyping. We would also like to thank Jan Paul Medema and Hans Clevers for their generous gift of the LGR5 knockdown constructs.

\section{Authors' contributions}

C.H., V.P., and Z.W. designed research and supervised the research; C.H., V.P., V.S., C-Y.W., C.L., R.B., C.K., M.O., A.N., and A.B. performed the research; K.J. contributed with the breast cancer TMA, F.W. contributed with the DCIS TMA, O.D.K. contributed to the animal studies, C.H., V.P., V.S., M.O., and C-Y.W analysed data; C.H., V.P. M.O., and V.S. wrote the manuscript, and all authors have discussed the results, provided critical comments and feedback, and read and approved the manuscript.

\section{Funding}

Study design, experimental workup, data collection, analysis and interpretation for this manuscript were supported by a Cancer League award (to V.P. and Z.W.), by grants from the National Cancer Institute (CA057621, CA180039, CA199315 and (A190851), and California Breast Cancer Research Program [23|B-001] (to Z.W.), by a grant from the National Institutes of Dental and Craniofacial Research (R35_DE026602 to O.D.K.),by funds from the Tegger Foundation, Wenner-Gren Foundations, Sweden-America Foundation, Swedish Society of Medicine, Maggie Stephens, Läkaresällskapet i Lund and Swedish Society for Medical Research (to C.H.) and by the Taiwan Ministry of Science and Technology Grant MOST104-2917-I-006-002 (to C-Y. W.). Grants to V.P., Z.W., and O.D.K., were used for pre-clinical in vitro and in vivo experiments, and grants to C.H. and C-Y.W. were used for analysis of clinical samples.

\section{Availability of data and materials}

The datasets used and/or analysed during the current study are available from the corresponding author(s) on reasonable request.

\section{Ethics approval and consent to participate}

Written ethical permit for the DCIS TMA was approved from the ethical committee at Uppsala University Hospital. Written ethical permit for the BC TMA was approved from the ethical committee at Lund University. Informed consent is deemed unnecessary according to national regulations; ethical committees at Uppsala University Hospital and Lund University. All cell lines used in our study does not require any ethical approval. Animal experiments in our study were performed according to the Institutional Animal Care and Use Committee (IACUC) guidelines. All procedures have written approval through IACUC by The University of California, San Francisco and Washington University.

\section{Consent for publication}

Written consent is provided by all the authors and participants for use of individual details and images.

\section{Competing interests}

The authors declare that they have no competing interests.

\section{Author details}

${ }^{1}$ Department of Anatomy and the Helen Diller Family Comprehensive Cancer Center, University of California, San Francisco, CA 94143-0452, USA. ${ }^{2}$ Department of Clinical Sciences Lund, Division of Oncology and Pathology, Lund University, SE-221 85 Lund, Sweden. ${ }^{3}$ Present Address: Department of Laboratory Medicine, Division of Clinical Genetics, Lund University, SE-221 85 Lund, Sweden. ${ }^{4}$ Department of Biochemistry and Molecular Biology, Institute of Basic Medical Sciences, College of Medicine, National Cheng Kung University, Tainan, Taiwan. ${ }^{5}$ Present Address: Radiotherapy and Oncoimmunology Laboratory, Department of Radiation Oncology, Radboud University Medical Center, Geert Grooteplein Zuid 32, 6525 GA Nijmegen, 
Netherlands. ${ }^{6}$ Present Address: Department of Medical Physiology, Division of Heart \& Lungs, University Medical Center Utrecht, Yalelaan 50, 3584CM Utrecht, Netherlands. 'Hubrecht Institute, Royal Netherlands Academy of Arts and Sciences (KNAW), University Medical Centre Utrecht, 3584CT Utrecht, Netherlands. ${ }^{8}$ Present Address: ICCE Institute, School of Medicine, Department of Medicine, Washington University, St Louis, MO 63110, USA. ${ }^{9}$ Department of Surgery, Institute of Clinical Sciences, Sahlgrenska Academy at the University of Gothenburg, Sahlgrenska University Hospital, S413 45 Gothenburg, Sweden. ${ }^{10}$ Department of Orofacial Sciences, University of California, 513 Parnassus Avenue, San Francisco, CA 94143-0452, USA. ${ }^{11}$ Institute for Human Genetics, University of California, San Francisco, San Francisco, CA 94143, USA.

\section{Received: 4 November 2019 Accepted: 20 May 2020} Published online: 10 June 2020

\section{References}

1. Bleyer A, Welch HG. Effect of three decades of screening mammography on breast-cancer incidence. N Engl J Med. 2012;367(21):1998-2005.

2. Gotzsche PC, Nielsen M. Screening for breast cancer with mammography. Cochrane Database Syst Rev. 2011;1:CD001877.

3. Katz SJ, Morrow M. Addressing overtreatment in breast cancer: the doctors' dilemma. Cancer. 2013;119(20):3584-8.

4. Welch HG, Prorok PC, O'Malley AJ, Kramer BS. Breast-Cancer tumor size, Overdiagnosis, and mammography screening effectiveness. N Engl J Med. 2016;375(15):1438-47.

5. Perou CM, Sorlie T, Eisen MB, van de Rijn M, Jeffrey SS, Rees CA, Pollack JR, Ross DT, Johnsen $H$, Akslen LA, et al. Molecular portraits of human breast tumours. Nature. 2000;406(6797):747-52.

6. Sorlie T, Perou CM, Tibshirani R, Aas T, Geisler S, Johnsen H, Hastie T, Eisen $M B$, van de Rijn M, Jeffrey SS, et al. Gene expression patterns of breast carcinomas distinguish tumor subclasses with clinical implications. Proc Natl Acad Sci U S A. 2001:98(19):10869-74.

7. Allred DC, Brown P, Medina D. The origins of estrogen receptor alphapositive and estrogen receptor alpha-negative human breast cancer. Breast Cancer Res. 2004;6(6):240-5.

8. Sotiriou C, Pusztai L. Gene-expression signatures in breast cancer. N Engl J Med. 2009;360(8):790-800.

9. Burstein HJ, Polyak K, Wong JS, Lester SC, Kaelin CM. Ductal carcinoma in situ of the breast. N Engl J Med. 2004;350(14):1430-41.

10. Shoker BS, Sloane JP. DCIS grading schemes and clinical implications. Histopathology. 1999;35(5):393-400.

11. Siziopikou KP. Ductal carcinoma in situ of the breast: current concepts and future directions. Arch Pathol Lab Med. 2013;137(4):462-6.

12. Jones JL. Overdiagnosis and overtreatment of breast cancer: progression of ductal carcinoma in situ: the pathological perspective. Breast Cancer Res. 2006;8(2):204.

13. Bijker N, Peterse $J$, Duchateau L, Julien JP, Fentiman IS, Duval C, Di Palma S, Simony-Lafontaine J, de Mascarel I, van de Vijver MJ. Risk factors for recurrence and metastasis after breast-conserving therapy for ductal carcinoma-in-situ: analysis of European Organization for Research and Treatment of Cancer trial 10853. J Clin Oncol. 2001;19(8):2263-71.

14. Page DL, Dupont WD, Rogers LW, Jensen RA, Schuyler PA. Continued local recurrence of carcinoma 15-25 years after a diagnosis of low grade ductal carcinoma in situ of the breast treated only by biopsy. Cancer. 1995;76(7):1197-200.

15. Page $\mathrm{DL}$, Dupont WD, Rogers LW, Landenberger M. Intraductal carcinoma of the breast: follow-up after biopsy only. Cancer. 1982;49(4):751-8.

16. lakovlev W, Arneson NC, Wong V, Wang C, Leung S, lakovleva G, Warren K, Pintilie M, Done SJ. Genomic differences between pure ductal carcinoma in situ of the breast and that associated with invasive disease: a calibrated aCGH study. Clin Cancer Res. 2008;14(14):4446-54.

17. Kim SY, Jung SH, Kim MS, Baek IP, Lee SH, Kim TM, Chung YJ, Lee SH. Genomic differences between pure ductal carcinoma in situ and synchronous ductal carcinoma in situ with invasive breast cancer. Oncotarget. 2015;6(10):7597-607.

18. Sanders ME, Schuyler PA, Dupont WD, Page DL. The natural history of low-grade ductal carcinoma in situ of the breast in women treated by biopsy only revealed over 30 years of long-term follow-up. Cancer. 2005;103(12):2481-4.
19. Collins LC, Tamimi RM, Baer HJ, Connolly JL, Colditz GA, Schnitt SJ. Outcome of patients with ductal carcinoma in situ untreated after diagnostic biopsy: results from the Nurses' health study. Cancer. 2005; 103(9):1778-84.

20. Lannin DR, Wang S. Are small breast cancers good because they are small or small because they are good? N Engl J Med. 2017:376(23):2286-91.

21. Siegel RL, Miller KD, Jemal A. Cancer statistics, 2018. CA Cancer J Clin. 2018; 68(1):7-30.

22. Dent R, Trudeau M, Pritchard Kl, Hanna WM, Kahn HK, Sawka CA, Lickley LA, Rawlinson E, Sun P, Narod SA. Triple-negative breast Cancer: clinical features and patterns of recurrence. Clin Cancer Res. 2007;13(15):4429.

23. Carey LA. Directed therapy of subtypes of triple-negative breast cancer. Oncologist. 2010;15(Suppl 5):49-56.

24. Foulkes WD, Smith IE, Reis-Filho JS. Triple-negative breast cancer. N Engl J Med. 2010;363(20):1938-48.

25. Bertucci F, Finetti P, Cervera N, Esterni B, Hermitte F, Viens P, Birnbaum D. How basal are triple-negative breast cancers? Int J Cancer. 2008;123(1):236-40.

26. Bayraktar S, Gluck S. Molecularly targeted therapies for metastatic triplenegative breast cancer. Breast Cancer Res Treat. 2013;138(1):21-35.

27. Schmid P, Adams S, Rugo HS, Schneeweiss A, Barrios CH, Iwata H, Dieras V, Hegg R, Im SA, Shaw Wright G, et al. Atezolizumab and nabpaclitaxel in advanced triple-negative breast Cancer. N Engl J Med. 2018:379(22):2108-21.

28. Leung C, Tan SH, Barker N. Recent advances in Lgr5(+) stem cell research. Trends Cell Biol. 2018;28(5):380-91.

29. Barker N, van Es JH, Kuipers J, Kujala P, van den Born M, Cozijnsen M, Haegebarth A, Korving J, Begthel H, Peters PJ, et al. Identification of stem cells in small intestine and colon by marker gene Lgr5. Nature. 2007; 449(7165):1003-7.

30. Barker N, Huch M, Kujala P, van de Wetering M, Snippert HJ, van Es JH, Sato $\mathrm{T}$, Stange DE, Begthel $\mathrm{H}$, van den Born $\mathrm{M}$, et al. Lgr5(+ve) stem cells drive self-renewal in the stomach and build long-lived gastric units in vitro. Cell Stem Cell. 2010;6(1):25-36.

31. Barker N, van Es JH, Jaks V, Kasper M, Snippert H, Toftgard R, Clevers H. Very long-term self-renewal of small intestine, colon, and hair follicles from cycling Lgr5+ve stem cells. Cold Spring Harb Symp Quant Biol. 2008;73:351-6.

32. Barker N, Rookmaaker MB, Kujala P, Ng A, Leushacke M, Snippert H, van de Wetering M, Tan S, Van Es JH, Huch M, et al. Lgr5(+ve) stem/progenitor cells contribute to nephron formation during kidney development. Cell Rep. 2012;2(3):540-52.

33. Plaks V, Brenot A, Lawson DA, Linnemann JR, Van Kappel EC, Wong KC, de Sauvage F, Klein OD, Werb Z. Lgr5-expressing cells are sufficient and necessary for postnatal mammary gland organogenesis. Cell Rep. 2013; 3(1):70-8.

34. de Visser KE, Ciampricotti M, Michalak EM, Tan DW, Speksnijder EN, Hau CS, Clevers H, Barker N, Jonkers J. Developmental stage-specific contribution of LGR5(+) cells to basal and luminal epithelial lineages in the postnatal mammary gland. J Pathol. 2012;228(3):300-9.

35. Trejo CL, Luna G, Dravis C, Spike BT, Wahl GM. Lgr5 is a marker for fetal mammary stem cells, but is not essential for stem cell activity or tumorigenesis. NPJ Breast Cancer. 2017;3:16.

36. Koren S, Reavie L, Couto JP, De Silva D, Stadler MB, Roloff T, Britschgi A, Eichlisberger $\mathrm{T}$, Kohler $\mathrm{H}$, Aina $\mathrm{O}$, et al. PIK3CA(H1047R) induces multipotency and multi-lineage mammary tumours. Nature. 2015; 525(7567):114-8.

37. Yang L, Tang H, Kong Y, Xie X, Chen J, Song C, Liu X, Ye F, Li N, Wang N, et al. LGR5 promotes breast Cancer progression and maintains stem-like cells through activation of Wnt/beta-catenin signaling. Stem Cells. 2015; 33(10):2913-24

38. Lawson DA, Bhakta NR, Kessenbrock K, Prummel KD, Yu Y, Takai K, Zhou A Eyob H, Balakrishnan S, Wang CY, et al. Single-cell analysis reveals a stemcell program in human metastatic breast cancer cells. Nature. 2015; 526(7571):131-5.

39. Plaks V, Kong N, Werb Z. The cancer stem cell niche: how essential is the niche in regulating stemness of tumor cells? Cell Stem Cell. 2015;16(3):225-38.

40. $\mathrm{Xu} \mathrm{L,} \mathrm{Lin} \mathrm{W,} \mathrm{Wen} \mathrm{L,} \mathrm{Li} \mathrm{G.} \mathrm{Lgr5} \mathrm{in} \mathrm{cancer} \mathrm{biology:} \mathrm{functional} \mathrm{identification} \mathrm{of}$ Lgr5 in cancer progression and potential opportunities for novel therapy. Stem Cell Res Ther. 2019;10(1):219.

41. Borgquist S, Jogi A, Ponten F, Ryden L, Brennan DJ, Jirstrom K. Prognostic impact of tumour-specific HMG-CoA reductase expression in primary breast cancer. Breast Cancer Res. 2008;10(5):R79. 
42. Zhou W, Jirstrom K, Amini RM, Fjallskog ML, Sollie T, Lindman H, Sorlie T, Blomqvist C, Warnberg F. Molecular subtypes in ductal carcinoma in situ of the breast and their relation to prognosis: a population-based cohort study. BMC Cancer. 2013;13:512.

43. Kemper K, Prasetyanti PR, De Lau W, Rodermond H, Clevers H, Medema JP. Monoclonal antibodies against Lgr5 identify human colorectal cancer stem cells. Stem Cells. 2012;30(11):2378-86.

44. Green JE, Shibata M-A, Yoshidome K, Liu M-L, Jorcyk C, Anver MR, Wigginton J, Wiltrout R, Shibata E, Kaczmarczyk S, et al. The C3(1)/SV40 T-antigen transgenic mouse model of mammary cancer: ductal epithelial cell targeting with multistage progression to carcinoma. Oncogene. 2000;19(8):1020-7.

45. Owyong M, Chou J, van den Bijgaart RJ, Kong N, Efe G, Maynard C, TalmiFrank D, Solomonov I, Koopman C, Hadler-Olsen E, et al. MMP9 modulates the metastatic cascade and immune landscape for breast cancer antimetastatic therapy. Life Sci Alliance. 2019;2(6):e201800226.

46. Alspach E, Flanagan KC, Luo X, Ruhland MK, Huang H, Pazolli E, Donlin MJ, Marsh T, Piwnica-Worms D, Monahan J, et al. p38MAPK plays a crucial role in stromal-mediated tumorigenesis. Cancer Discov. 2014;4(6):716-29.

47. Hahn WC, Counter CM, Lundberg AS, Beijersbergen RL, Brooks MW, Weinberg RA. Creation of human tumour cells with defined genetic elements. Nature. 1999;400(6743):464-8.

48. Elkabets M, Gifford AM, Scheel C, Nilsson B, Reinhardt F, Bray MA, Carpenter $A E$, Jirstrom $K$, Magnusson $K$, Ebert BL, et al. Human tumors instigate granulin-expressing hematopoietic cells that promote malignancy by activating stromal fibroblasts in mice. J Clin Invest. 2011;121(2):784-99.

49. DeRose YS, Wang G, Lin YC, Bernard PS, Buys SS, Ebbert MT, Factor R, Matsen C, Milash BA, Nelson E, et al. Tumor grafts derived from women with breast cancer authentically reflect tumor pathology, growth, metastasis and disease outcomes. Nat Med. 2011;17(11):1514-20.

50. Maroulakou IG, Anver M, Garrett L, Green JE. Prostate and mammary adenocarcinoma in transgenic mice carrying a rat C3(1) simian virus 40 large tumor antigen fusion gene. Proc Natl Acad Sci U S A. 1994;91(23): $11236-40$

51. Rhodes DR, Kalyana-Sundaram S, Mahavisno V, Varambally $R, Y u$ J, Briggs BB, Barrette TR, Anstet MJ, Kincead-Beal C, Kulkarni P, et al. Oncomine 3.0: genes, pathways, and networks in a collection of 18,000 cancer gene expression profiles. Neoplasia. 2007;9(2):166-80.

52. McShane LM, Altman DG, Sauerbrei W, Taube SE, Gion M, Clark GM. Statistics subcommittee of the NCIEWGoCD: REporting recommendations for tumor MARKer prognostic studies (REMARK). Nat Clin Pract Urol. 2005; 2(8):416-22

53. Shi S, Chen X, Liu H, Yu K, Bao Y, Chai J, Gao H, Zou L. LGR5 acts as a target of miR-340-5p in the suppression of cell progression and drug resistance in breast cancer via Wnt/ß-catenin pathway. Gene. 2019;683:47-53.

54. Chen Z, Xue C. G-protein-coupled receptor 5 (LGR5) overexpression activates $\beta$-catenin signaling in breast Cancer cells via protein kinase a. Med Sci Monit Basic Res. 2019:25:15-25.

55. Hidalgo M, Amant F, Biankin AV, Budinská E, Byrne AT, Caldas C, Clarke RB, de Jong S, Jonkers J, Mælandsmo GM, et al. Patient-derived xenograft models: an emerging platform for translational cancer research. Cancer Discov. 2014;4(9):998-1013

56. Junttila MR, Mao W, Wang X, Wang BE, Pham T, Flygare J, Yu SF, Yee S, Goldenberg D, Fields C, et al. Targeting LGR5+ cells with an antibody-drug conjugate for the treatment of colon cancer. Sci Transl Med. 2015;7(314): 314 ra186.

57. Hou MF, Chen PM, Chu PY. LGR5 overexpression confers poor relapse-free survival in breast cancer patients. BMC Cancer. 2018;18(1):219.

58. Anderson WF, Rosenberg PS, Prat A, Perou CM, Sherman ME. How many etiological subtypes of breast cancer: two, three, four, or more? J Natl Cancer Inst. 2014;106(8):dju165.

59. Zhang L, Adileh M, Martin ML, Klingler S, White J, Ma X, Howe LR, Brown AM, Kolesnick R. Establishing estrogen-responsive mouse mammary organoids from single Lgr5(+) cells. Cell Signal. 2017;29:41-51.

60. Fu NY, Rios AC, Pal B, Law CW, Jamieson P, Liu R, Vaillant F, Jackling F, Liu KH, Smyth GK, et al. Identification of quiescent and spatially restricted mammary stem cells that are hormone responsive. Nat Cell Biol. 2017;19(3):164-76.

61. Ryan BM, Faupel-Badger JM. The hallmarks of premalignant conditions: a molecular basis for cancer prevention. Semin Oncol. 2016;43(1):22-35.

62. Lopez-Garcia MA, Geyer FC, Lacroix-Triki M, Marchio C, Reis-Filho JS. Breast cancer precursors revisited: molecular features and progression pathways. Histopathology. 2010;57(2):171-92.
63. Oskarsson T, Acharyya S, Zhang XH, Vanharanta S, Tavazoie SF, Morris PG, Downey RJ, Manova-Todorova K, Brogi E, Massague J. Breast cancer cells produce tenascin $C$ as a metastatic niche component to colonize the lungs. Nat Med. 2011;17(7):867-74.

\section{Publisher's Note}

Springer Nature remains neutral with regard to jurisdictional claims in published maps and institutional affiliations.
Ready to submit your research? Choose BMC and benefit from:

- fast, convenient online submission

- thorough peer review by experienced researchers in your field

- rapid publication on acceptance

- support for research data, including large and complex data types

- gold Open Access which fosters wider collaboration and increased citations

- maximum visibility for your research: over $100 \mathrm{M}$ website views per year

At BMC, research is always in progress.

Learn more biomedcentral.com/submissions 